\title{
Impacto energético da irrigação por gotejamento no cultivo de mamona ${ }^{1}$
}

\author{
Rodrigo Aparecido Jordan ${ }^{2}$, Eder Pereira Gomes ${ }^{2}$, \\ Guilherme Augusto Biscaro ${ }^{2}$, Anamari Viegas de Araújo Motomiya ${ }^{2}$, Luciano Geisenhoff ${ }^{2}$
}

\begin{abstract}
Energetic impact of

drip irrigation on castor bean crop

Irrigation is a technique with high potential to increase crop yield, however, it is necessary to evaluate the energetic efficiency of irrigated agriculture. So, this study aimed at evaluating the irrigation impact on grain yield and energetic balance of two castor bean cultivars submitted to supplementary drip irrigation with different water depths. The experiment was conducted in a clayey Dystrophic Purple Latosol, in Dourados, Mato Grosso do Sul State, Brazil. The experimental design was randomized blocks in a bifactorial scheme, with five water depths $(0 \%, 25 \%, 50 \%$, $100 \%$ and $150 \%$ of evapotranspiration for localized irrigation) and two castor bean cultivars (IAC 2028 and IAC 80), with four replications. The irrigation interval was of up to two irrigations per week, except for the days when rainfall occurred. Crop yield and the relation energy produced in the form of grains/energy used in cultivation were evaluated. It was concluded that the supplementary irrigation increased yield, as well as the relationship between energy production and consumption.
\end{abstract}

KEY-WORDS: Ricinus communis L.; energetic balance; supplementary irrigation.

\section{INTRODUÇÃO}

A mamoneira (Ricinus communis L.) é uma oleaginosa de importância econômica e social, cujo óleo possui inúmeras aplicações na área industrial e perspectivas de utilização como fonte energética, na produção de biocombustível (Severino et al. 2006). Segundo Santos et al. (2001), a mamoneira vem sendo explorada em vários países, sendo os principais produtores a Índia, China, Brasil e Rússia, tanto sob cultivo irrigado quanto sequeiro. No Brasil, é cultivada, principalmente, nos Estados do Nordeste e Centro-Oeste (Corrêa et al. 2006, Costa et al. 2009),

\section{RESUMO}

A irrigação é uma técnica com alto potencial para aumentar a produtividade de culturas, entretanto, deve-se avaliar a eficiência energética da agricultura irrigada. Assim, objetivouse avaliar o impacto da irrigação na produtividade de grãos e no balanço energético de duas cultivares de mamona, submetidas à irrigação suplementar por gotejamento, com diferentes lâminas de água. $\mathrm{O}$ experimento foi desenvolvido no município de Dourados (MS), em Latossolo Vermelho distroférrico, com textura argilosa. $\mathrm{O}$ delineamento experimental foi em blocos casualizados, em esquema bifatorial, com cinco lâminas de água $(0 \%, 25 \%, 50 \%$, $100 \%$ e $150 \%$ da evapotranspiração para irrigação localizada) e duas cultivares de mamona (IAC 2028 e IAC 80), com quatro repetições. O turno de rega foi pré-determinado em até duas irrigações semanais, excetuando-se os dias em que ocorreu precipitação pluviométrica. Foram avaliadas a produtividade da cultura e a relação energia produzida na forma de grãos/energia empregada no cultivo. Concluiu-se que a irrigação suplementar proporcionou incremento na produtividade, bem como na relação entre a quantidade de energia extraída e energia empregada.

PALAVRAS-CHAVE: Ricinus communis L.; balanço energético; irrigação suplementar.

devido ao interesse pela indústria ricinoquímica e pela busca de fontes energéticas.

O principal produto da mamona é o óleo de rícino, que é uma importante matéria-prima para a indústria química, com larga utilização na composição de inúmeros produtos, tais como tintas, vernizes, cosméticos, fluidos hidráulicos e plásticos (Costa et al. 2010). Entretanto, o óleo de rícino extraído da semente começou a ser visto como meio produtivo para a obtenção de biodiesel, que é um combustível renovável.

Segundo Hülsbergen et al. (2001), as culturas devem apresentar, além da viabilidade econômica,

1. Trabalho recebido em mar./2012 e aceito para publicação em nov./2012 ( ${ }^{\circ}$ registro: PAT 17534).

2. Universidade Federal da Grande Dourados (UFGD), Faculdade de Ciências Agrárias, Dourados, MS, Brasil. E-mails: rodrigojordan@ufgd.edu.br, guilhermebiscaro@ufgf.edu.br, anamarimotomiya@ufgd.edu.br, edergomes@ufgd.edu.br, lucianogeisenhoff@ufgd.edu.br. 
viabilidade energética. Entretanto, como a produção agrícola moderna é caracterizada por um alto consumo de energia fóssil e recursos naturais, as produtividades devem ser expressivas, para se ter um balanço de energia significativo. Embora a irrigação seja uma técnica com alto potencial para aumentar a produtividade das culturas, poucos trabalhos têm abordado a eficiência energética da agricultura irrigada (Carvalho et al. 2008).

As demandas por alternativas de renda para o meio rural, aliadas aos investimentos do Governo Federal para a diversificação de oleaginosas, para a produção de biodiesel, colocam a mamona em destaque, como uma cultura potencial para estes fins (César \& Batalha 2011, Eicholz \& Silva 2011). Silva et al. (2010) salientam que, embora a mamona não participe efetivamente do programa brasileiro de biocombustíveis, e que seu uso principal não esteja direcionado para a produção de energia, estudos sobre esta oleaginosa fornecem subsídios para a avaliação energética de outras culturas.

Além da questão do preço, devido à valorização do óleo perante a indústria química, outra característica responsável por a mamona perder espaço para outras oleaginosas, na produção de biodiesel, apontada por Lôbo et al. (2009), é a elevada solubilidade do óleo de mamona em alcoóis, sendo uma das grandes dificuldades encontradas na produção de biodiesel por meio da transesterificação, que é a separação da glicerina e do álcool do biodiesel, de forma a atender às especificações da Agência Nacional do Petróleo, Gás Natural e Biocombustíveis (ANP).

O balanço energético é o parâmetro mais adequado para definir a viabilidade técnica de um programa de bioenergia. Para ser positivo, o balanço energético depende de diversos fatores, especialmente do rendimento da cultura e do menor consumo de fertilizantes nitrogenados (Gazzoni et al. 2007). Para Campos \& Campos (2004), o balanço energético é um importante instrumento para a tomada de decisões relativas à adoção de novas técnicas e manejos agropecuários, com potencial para economizar energia e aumentar a eficiência dos insumos, reduzindo custos em sistemas de produção.

Assim, objetivou-se avaliar o impacto da irrigação suplementar na produtividade de grãos e no balanço energético de duas cultivares de mamona submetidas à irrigação por um sistema localizado de gotejamento, com diferentes lâminas de água.

\section{MATERIAL E MÉTODOS}

O experimento foi desenvolvido no ano agrícola de 2009, em área experimental da Faculdade de Ciências Agrárias da Universidade Federal da Grande Dourados (UFGD) $\left(22^{\circ} 13^{\prime} 16^{\prime \prime} \mathrm{S}, 54^{\circ} 17^{\prime} 01^{\prime \prime} \mathrm{W}\right.$ e altitude média de $452 \mathrm{~m}$ ), em Dourados (MS). O clima local é do tipo Cwa (clima temperado e úmido, com inverno seco e verão quente), segundo a classificação de Köppen-Geiger.

O solo da área foi classificado como Latossolo Vermelho distroférrico (Embrapa 2006), de textura muito argilosa e com as seguintes características: $\mathrm{pH}\left(\mathrm{CaCl}_{2}\right)=5,3 ; \mathrm{M} . \mathrm{O}=8,0 \mathrm{~g} \mathrm{~kg}^{-1}$; P-resina $=5 \mathrm{mg} \mathrm{dm}{ }^{-3} ; \mathrm{K}^{+}=0,15 \mathrm{cmol}_{\mathrm{c}} \mathrm{dm}^{-3} ; \mathrm{Ca}^{2+}=$ $3,31 \mathrm{cmol}_{\mathrm{c}} \mathrm{dm}^{-3} ; \mathrm{Mg}^{2+}=2,52 \mathrm{cmol}_{\mathrm{c}} \mathrm{dm}^{-3} ; \mathrm{H}^{+} \mathrm{Al}=$ $5,5 \mathrm{cmol}_{\mathrm{c}} \mathrm{dm}^{-3} ; \mathrm{CTC}=11,49 \mathrm{cmol}_{\mathrm{c}} \mathrm{dm}^{-3} ; \mathrm{e} \mathrm{V}=52 \%$. Como cultura antecessora, a soja foi colhida em 20 de março de 2009, dois meses antes da semeadura da mamona. O preparo do solo foi composto por uma aração e duas gradagens, 15 dias antes do plantio.

Utilizou-se o delineamento experimental em blocos casualizados, em esquema fatorial $5 \times 2$ (quantitativo e qualitativo, respectivamente), formado por cinco lâminas de irrigação $(0 \%, 25 \%, 50 \%$, $100 \%$ e $150 \%$ da evapotranspiração para irrigação localizada - ETLOC) e duas cultivares de mamona (IAC 2028 e IAC 80), com quatro repetições. As cinco lâminas de irrigação correspondentes, obtidas a partir das percentagens de evapotranpiração, foram $0 \mathrm{~mm}$, $27 \mathrm{~mm}, 54 \mathrm{~mm}, 108 \mathrm{~mm}$ e $162 \mathrm{~mm}$, respectivamente.

A cultivar IAC 2028 apresenta porte baixo $(150,0-180,0 \mathrm{~cm})$, frutos indeiscentes, moderada susceptibilidade a doenças (em especial ao mofo-cinzento), teor de óleo em torno de $47 \%$ e produtividade média variando de $1.500 \mathrm{~kg} \mathrm{ha}^{-1} \mathrm{a}$ $2.800 \mathrm{~kg} \mathrm{ha}^{-1}$. A cultivar IAC 80 apresenta porte alto $(250,0-300,0 \mathrm{~cm})$, frutos deiscentes com espinhos, teor de óleo entre $47 \%$ e $49 \%$ e produtividade média variando de $1.500 \mathrm{~kg} \mathrm{ha}^{-1}$ a $4.000 \mathrm{~kg} \mathrm{ha}^{-1}$.

A semeadura foi realizada manualmente, no dia 12/05/2009, quando foram distribuídas três sementes por cova $\left(18,0 \mathrm{~kg}\right.$ de semente ha- $\left.{ }^{-1}\right)$. Após 10 dias da germinação, foi realizado o desbaste. Cada unidade experimental (parcela) foi constituída por quatro linhas, nas quais permaneceram cinco plantas cada, com espaçamento de $1,0 \mathrm{~m}$ x 1,0 m. A adubação de cobertura foi realizada com $60 \mathrm{~kg}$ de $\mathrm{N} \mathrm{ha}^{-1}$ (ureia), $90 \mathrm{~kg}$ de $\mathrm{P}_{2} \mathrm{O}_{5} \mathrm{ha}^{-1}$ (superfosfato simples) e 
$60 \mathrm{~kg}$ de $\mathrm{K}_{2} \mathrm{O}$ ha-1 (cloreto de potássio). As plantas daninhas foram controladas, durante o experimento, utilizando-se capina manual.

O sistema de irrigação empregado foi do tipo localizado por gotejamento, com mangueiras gotejadoras de espessura de $200,0 \mu \mathrm{m}$ e espaçamento de $0,30 \mathrm{~m}$ entre emissores, sendo instalada uma mangueira gotejadora por linha cultivada. A vazão dos gotejadores foi determinada em campo, para uma pressão de serviço constante de 8,4 m.c.a., obtendo-se uma média por gotejador de 1,34 $\mathrm{L}$ hora $^{-1}$. A pressão de serviço foi monitorada com o uso de manômetros portáteis, por meio de tomadas de pressão instaladas na tubulação de derivação, para as linhas laterais de cada parcela.

O manejo da irrigação foi realizado com base nos dados calculados em uma planilha eletrônica (Bernardo et al. 2005) e em um valor único de Kc $(0,73)$, que representa a média dos valores de Kc, nos diferentes estádios da cultura, para a região de Santo Antônio do Leverger (MT) (Curi 2004), juntamente com as informações de evapotranspiração de referência fornecidas pela estação meteorológica automatizada pertencente à Universidade Federal da Grande Dourados.

O turno de rega adotado foi de quatro dias entre irrigações, excetuando-se os períodos em que ocorreram precipitações, quando, então, era recalculado o momento exato da próxima irrigação. O controle do tempo de irrigação e da lâmina de água aplicada foi realizado manualmente, por meio de registros individuais para cada tratamento.

Durante o período de execução do experimento, ocorreram 64 precipitações, sendo realizadas 18 irrigações suplementares. Estas foram suspensas a partir do dia 03/09/2009, quando a planta atingiu o estado de maturação.

No dia 30/10/2009, realizou-se, de forma manual, uma única colheita da cultura, na qual todos os cachos da planta atingiram a maturidade fisiológica. Considerou-se área útil as duas linhas centrais de cada parcela, desprezando-se $0,5 \mathrm{~m}$ em suas extremidades. O material colhido foi seco à sombra e limpo, para realização da debulha manual e posterior armazenamento.

Após a debulha, o tempo de armazenagem dos grãos foi de 6 meses, sendo, após este período, obtida a massa dos grãos (1.000 grãos por parcela) e, posteriormente, determinada a produtividade da cultura, com umidade média de 10\%. Determinou-se o teor de óleo dos grãos, em três amostras, com base nos procedimentos definidos pela IUPAC (Paquot 1979). O aparelho utilizado foi o extrator Soxhlet Marconi ma 491/06.

No balanço energético, determinou-se a relação entre a energia extraída na forma de grãos e a energia empregada durante o cultivo e a colheita. No caso da energia empregada, foram somadas todas as entradas de energia: diretas (fertilizantes, combustíveis, lubrificantes, mão de obra e energia elétrica, no caso dos tratamentos irrigados) e indiretas (equipamentos: trator, implementos agrícolas e sistema de irrigação, no caso dos tratamentos irrigados).

No cálculo da energia relativa aos fertilizantes, utilizou-se a metodologia adotada por Melo et al. (2007). As equivalências energéticas da energia elétrica e do óleo diesel foram retiradas do Balanço Energético Nacional de 2008 (EPE 2008, Tabela 1).

A quantificação da energia referente aos equipamentos empregados foi realizada de acordo com Assenheimer et al. (2009), segundo a vida útil, a massa e os respectivos coeficientes energéticos. Os coeficientes energéticos adotados (Assenheimer et al. 2009) foram 69,83 $\mathrm{MJ} \mathrm{kg}^{-1}$, para equipamentos autopropelidos, e 57,20 $\mathrm{MJ} \mathrm{kg}^{-1}$, para equipamentos não propelidos. Para isto, foram empregadas as seguintes equações:

$$
E a p=\frac{69,83 \times M}{V u} \text { e } E n p=\frac{57,20 \times M}{V u},
$$

onde Eap é a energia de equipamento autopropelido $\left(\mathrm{MJ} \mathrm{h}^{-1}\right)$, Enp a energia de equipamento não autopropelido $\left(\mathrm{MJ} \mathrm{h}^{-1}\right), M$ a massa do equipamento $(\mathrm{kg})$ e $V u$ a vida útil do equipamento (h). Os dados dos equipamentos empregados (massa e vida útil) estão apresentados na Tabela 2.

Para o caso do sistema de irrigação por gotejamento com o uso de fitas gotejadoras, baseado na quantidade de fitas utilizadas no experimento,

Tabela 1. Equivalências energéticas empregadas para o cálculo do balanço enérgico do cultivo de mamona.

\begin{tabular}{lccc}
\hline \multirow{2}{*}{ Componente } & \multirow{2}{*}{ Unidade $\frac{\text { Energia }}{\mathrm{MJ}}$} & \multirow{2}{*}{ Fonte } \\
\hline Óleo diesel & $\mathrm{L}$ & 35,52 & EPE (2008) \\
Grãos de mamona & $\mathrm{kg}$ & 19,03 & Albuquerque et al. (2008) \\
Nitrogênio & $\mathrm{kg}$ & 50,28 & Melo et al. (2007) \\
Fósforo & $\mathrm{kg}$ & 12,57 & Melo et al. (2007) \\
Potássio & $\mathrm{kg}$ & 6,77 & Melo et al. (2007) \\
Energia elétrica & $\mathrm{kWh}$ & 3,60 & EPE (2008) \\
Mão de obra & $\mathrm{H}$ & 2,16 & Melo et al. (2007) \\
\hline
\end{tabular}


Tabela 2. Massa e vida útil dos equipamentos empregados para a quantificação do balanço enérgico no cultivo de mamona.

\begin{tabular}{lcc}
\hline \multirow{2}{*}{ Equipamento } & Massa & Vida útil \\
\cline { 2 - 3 } & $\mathrm{kg}$ & $\mathrm{h}$ \\
\hline Trator com pneus de $80 \mathrm{cv}$ & $3.000^{(2)}$ & $12.000^{(1)}$ \\
Equipamento de irrigação & 100 & 5.000 \\
Arado & $1.000^{(2)}$ & $5.000^{(3)}$ \\
Grade & $1.200^{(2)}$ & $3.000^{(3)}$ \\
Subsolador & $500^{(4)}$ & $2.000^{(1)}$ \\
\hline
\end{tabular}

${ }^{1}$ Pacheco (2000); ${ }^{2}$ Assenheimer et al. (2009); ${ }^{3}$ Chechetto et al. (2010); ${ }^{4}$ Determinado a partir do equipamento empregado.

na massa por metro linear $\left(0,0068 \mathrm{~kg} \mathrm{~m}^{-1}\right)$ e no espaçamento utilizado, estimou-se a massa total para 1,0 hectare, sendo, também, considerada a massa do sistema de bombeamento e filtragem. A vida útil das fitas gotejadoras foi determinada por experiência prática, com base em trabalhos realizados no Campo Experimental, com este tipo de componente, onde foi verificada vida útil de três anos, que, traduzida em horas efetivas de uso (irrigação), resultou em vida útil em horas.

O tempo gasto em cada operação agrícola foi medido durante o período experimental, extrapolando-se para horas por hectare. Estimou-se, para 1,0 hectare, cerca de 1 hora de trabalho de trator, para abertura de sucos com subsolador; 12 horas homem ${ }^{-1}$, para semeadura manual; mais 12 horas homem ${ }^{-1}$, para capina manual. Para preparo do solo, a estimativa para 1,0 hectare foi de 2,2 horas para aração e 1,4 horas para as duas gradagens. Para a colheita manual, considerando-se o corte dos cachos, transporte, secagem e debulha, estimou-se o tempo de 1 hora homem ${ }^{-1}$, para a obtenção de $10 \mathrm{~kg}$ de grãos de mamona.

O consumo de energia do sistema de irrigação foi determinado multiplicando-se a potência elétrica da bomba d'água pelo tempo de operação, o qual foi determinado com base na lâmina d'água aplicada em cada parcela e na capacidade de bombeamento, sendo, também, extrapolado para valores em hectare. O consumo de diesel para 1,0 hectare, com base no consumo verificado no preparo do experimento, foi estimado em $50 \mathrm{~L}$ para o preparo do solo (aração e gradagens) e $8 \mathrm{~L}$ para a semeadura (abertura de sulcos). A energia dos lubrificantes e filtros foi estimada em 5\% da energia do combustível (Chechetto et al. 2010). Os dados foram submetidos à análise de variância e regressão, a 1\% e 5\%, respectivamente.

\section{RESULTADOS E DISCUSSÃO}

A precipitação acumulada durante o período experimental foi de $736,1 \mathrm{~mm}$, com valores mensais crescentes, no decorrer do experimento, o que dificultou o manejo das lâminas de irrigação, já que mesmo as menores lâminas apresentaram bons resultados de produtividade.

Houve resposta quadrática $(\mathrm{p}<0,01)$ para a produtividade $\left(\mathrm{kg} \mathrm{ha}^{-1}\right)$, para as duas cultivares avaliadas, em função da lâmina de água aplicada (Figura 1). Com base na derivada das equações de regressão apresentadas, observou-se que as produtividades máximas de grãos seriam obtidas com as lâminas de $148,14 \%$ (160 mm) e 217,59\% (235 mm) da ETLOC, respectivamente para a IAC $80\left(1.497,83 \mathrm{~kg} \mathrm{ha}^{-1}\right) \mathrm{e}$ IAC $2028\left(1.526,84 \mathrm{~kg} \mathrm{ha}^{-1}\right)$.

Segundo Savy Filho et al. (1984 e 2007), as cultivares IAC 80 e IAC 2028, no Estado de São Paulo, apresentaram produtividades médias de $1.500 \mathrm{~kg} \mathrm{ha}^{-1} \mathrm{e} 1.950 \mathrm{~kg} \mathrm{ha}^{-1}$, respectivamente. Embora estes autores tenham evidenciado a superioridade da cultivar IAC 2028, em termos de produtividade, não foram observadas diferenças significativas entre as duas cultivares avaliadas neste estudo. Da mesma forma, o teor médio de óleo dos grãos foi de 34,6\%, não havendo diferença significativa entre as lâminas de água aplicadas ou entre as cultivares.

Em experimento avaliando lâminas de irrigação em Neossolo flúvico, cultivado com mamona cv. BRS Energia, Silva et al. (2009) obtiveram produtividade total de $1.317,09 \mathrm{~kg} \mathrm{ha}^{-1}$, para a lâmina aplicada de $487,5 \mathrm{~mm}$. Por outro lado, a mamona pode atingir rendimento

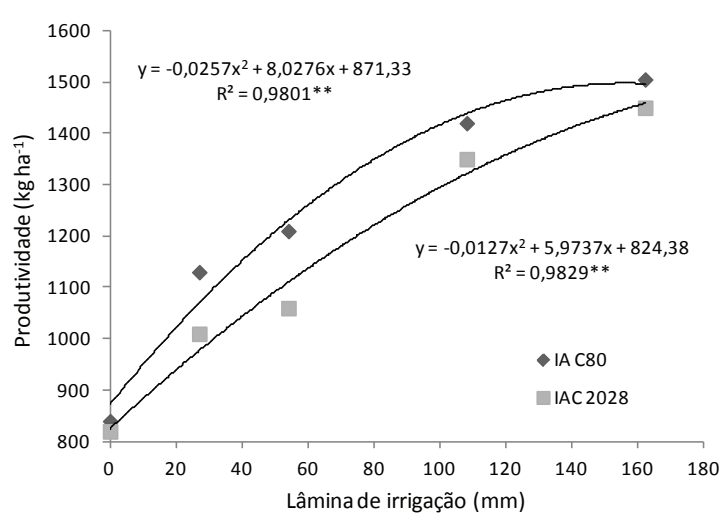

Figura 1. Produtividade de grãos de mamoneira (cultivares IAC 80 e IAC 2028), em função das lâminas de irrigação, até 140 dias após a semeadura (Dourados, MS, 2010). ** Significativo a $1 \%$, pelo teste $\mathrm{F}$. 
superior a $1.500 \mathrm{~kg} \mathrm{ha}^{-1}$, em zonas com precipitação pluvial acumulada superior a 700,0 $\mathrm{mm}$ (Weiss 1983).

Na Tabela 3, é possível observar as entradas de energia por etapa, na produção das duas cultivares, sendo que a etapa de manejo compreende a capina manual. Nota-se que a operação de semeadura foi a que demandou maior consumo energético, devido ao valor energético dos fertilizantes.

Relacionando-se a energia extraída na forma de grãos com a energia empregada para o cultivo e colheita, obteve-se o balanço energético da atividade agrícola (Figura 2), e, embora os resultados da análise de variância não tenham sido significativos, a irrigação aumentou o balanço energético. Segundo Campos \& Campos (2004), o balanço energético é um importante instrumento para selecionar tecnologias com potencial para economizar energia e aumentar a eficiência dos insumos, de forma a melhorar a eficiência produtiva do sistema agrícola. Verificou-se, independentemente das cultivares, tendência de decréscimo no valor do balanço energético a partir da lâmina de 108,0 mm (Figura 2), ou seja, a partir da lâmina d'água de $108,0 \mathrm{~mm}$, as repostas em termos de energia extraída são menores que os acréscimos de energia, para o fornecimento de uma lâmina d'água maior.

Todos os tratamentos apresentaram balanços positivos de energia, mesmo os que não receberam irrigação complementar, ou seja, o resultado do balanço energético foi superior à unidade. Isto deu-se pelo fato de as precipitações ocorridas situaremse na faixa correspondende a uma produtividade satisfatória para a cultura, tomando-se por base a produtividade média de algumas cultivares do Instituto Agronômico de Campinas (IAC), que variam entre $1.500 \mathrm{~kg} \mathrm{ha}^{-1}$ e $2.000 \mathrm{~kg} \mathrm{ha}^{-1}$. A suplementação hídrica, após a estação chuvosa ou durante a ocor-

Tabela 3. Entradas de energia (MJ ha-1) por etapa, em função dos tratamentos com irrigação suplementar, para as cultivares de mamoneira.

\begin{tabular}{lrccrr}
\hline \multirow{2}{*}{\multicolumn{1}{c}{ Etapas }} & \multicolumn{5}{c}{ Tratamentos } \\
\cline { 2 - 6 } & \multicolumn{1}{c}{$0 \%$} & $25 \%$ & $50 \%$ & $100 \%$ & $150 \%$ \\
\hline Preparo do solo & 1.947 & 1.947 & 1.947 & 1.947 & 1.947 \\
Semeadura & 5.272 & 5.272 & 5.272 & 5.272 & 5.272 \\
Manejo & 26 & 26 & 26 & 26 & 26 \\
Irrigação & 0 & 595 & 1.190 & 2.378 & 3.567 \\
Colheita IAC 80 & 181 & 244 & 261 & 307 & 325 \\
Colheita IAC 2028 & 177 & 218 & 229 & 292 & 313 \\
\hline Total IAC 80 & 7.426 & 8.084 & 8.696 & 9.930 & 11.137 \\
Total IAC 2028 & 7.423 & 8.059 & 8.665 & 9.916 & 11.126 \\
\hline
\end{tabular}

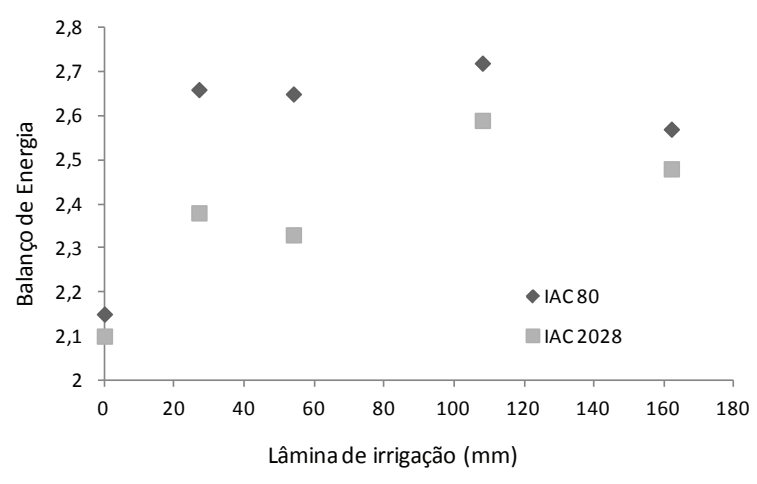

Figura 2. Balanço energético (energia extraída/energia empregada) para a produção das cultivares de mamoneira, até 140 dias após a semadura, em função das lâminas de irrigação suplementar (Dourados, MS, 2010).

rência de veranicos, pode contribuir para o aumento da produtividade, uma vez que, por tratar-se de uma planta de crescimento indeterminado, continuará a florescer e produzir (Souza et al. 2007).

Embora não tenha havido diferenças significativas entre as duas cultivares, em relação ao balanço energético, as menores relações de energia extraída/energia empregada foram obtidas sem irrigação (Figura 2). Na ausência de irrigação, as cultivares IAC 80 e IAC 2028 apresentaram balanço energético de 2,15 e 2,10, respectivamente. A maior relação $(2,72)$ foi obtida para a cultivar IAC 80 , com lâmina de irrigação de $108,0 \mathrm{~mm}$ e produtividade de $1.420 \mathrm{~kg} \mathrm{ha}^{-1}$. Para esta mesma lâmina, a cultivar IAC 2028 apresentou relação de 2,59.

Chechetto et al. (2010), trabalhando com mamona, verificaram valor de 2,45 , para a relação entre energia dos grãos e energia utilizada na fase agrícola (semeadura à colheita), para uma produtividade de $1.400 \mathrm{~kg} \mathrm{ha}^{-1}$ e colheita mecanizada, valores que corroboram os observados neste trabalho, no qual a cultivar IAC 2028 obteve produtividade de $1.452,4 \mathrm{~kg} \mathrm{ha}^{-1}$, para uma relação de 2,48.

Verifica-se que a etapa que consumiu mais energia foi a semeadura (Figura 3), na qual estão incluídos os fertilizantes, seguida da etapa de preparo do solo, onde houve o maior consumo de óleo diesel e lubrificantes, devido às operações de aração e gradagem. Para as lâminas de 108,0 mm e 162,0 mm, a etapa de irrigação superou o consumo energético da etapa de preparo do solo, pelo maior consumo de energia elétrica da bomba d'água do sistema de irrigação. As etapas de manejo e colheita foram as que 


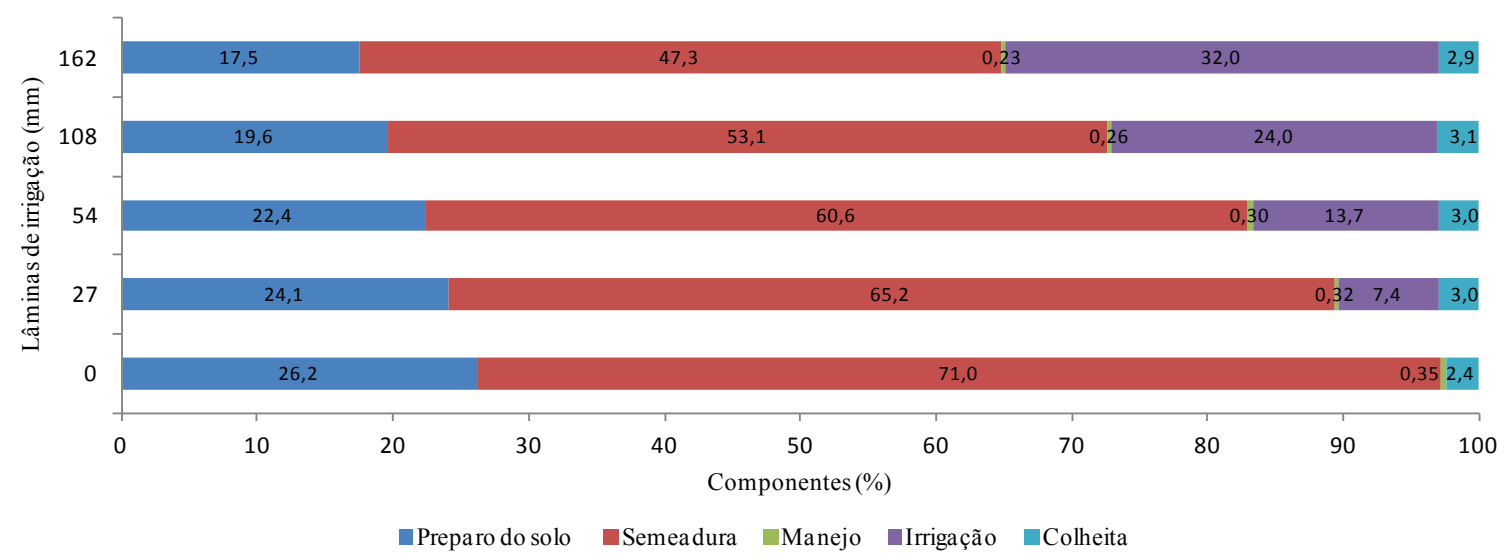

Figura 3. Participação de cada etapa nas entradas de energia para as duas cultivares de mamoneira, até 140 dias após a semadura, em função das lâminas de irrigação suplementar (Dourados, MS, 2010).

apresentaram a menor representatividade no consumo de energia, por envolverem trabalhos manuais.

Verificou-se que os fertilizantes são responsáveis pela maior parcela das entradas de energia (Figura 4), conforme também observaram Melo et al. (2007), Gazzoni et al. (2007) e Chechetto et al. (2010). Em segundo lugar, vem o óleo diesel e lubrificantes, sendo superados pela energia elétrica apenas no tratamento com lâmina de irrigação de 162,0 mm, onde esta representou $27 \%$ da energia empregada. Isto demonstra uma forte dependência de derivados de petróleo, a qual está presente em outras culturas destinadas à produção de biocombustíveis, como a cana-de-açúcar e a soja.

A mão de obra, sementes e equipamentos representaram itens que, quando comparados aos demais, atingiram menos de $6,0 \%$ do total da ener- gia empregada (Figura 4). Chechetto et al. (2010) consideraram desprezível a energia referente à mão de obra, em seu estudo, já que todas as operações foram mecanizadas. Campos et al. (2009), em experimento envolvendo o balanço energético com soja, observaram participação de $0,41 \%$ da mão de obra, nas entradas de energia.

\section{CONCLUSÕES}

1. O aumento nas lâminas de irrigação incrementou significativamente a produtividade das duas cultivares de mamona, sem alterar o teor de óleo contido nas sementes.

2. O impacto da irrigação no balanço energético das duas cultivares foi positivo, proporcionando aumento da relação entre a quantidade de energia

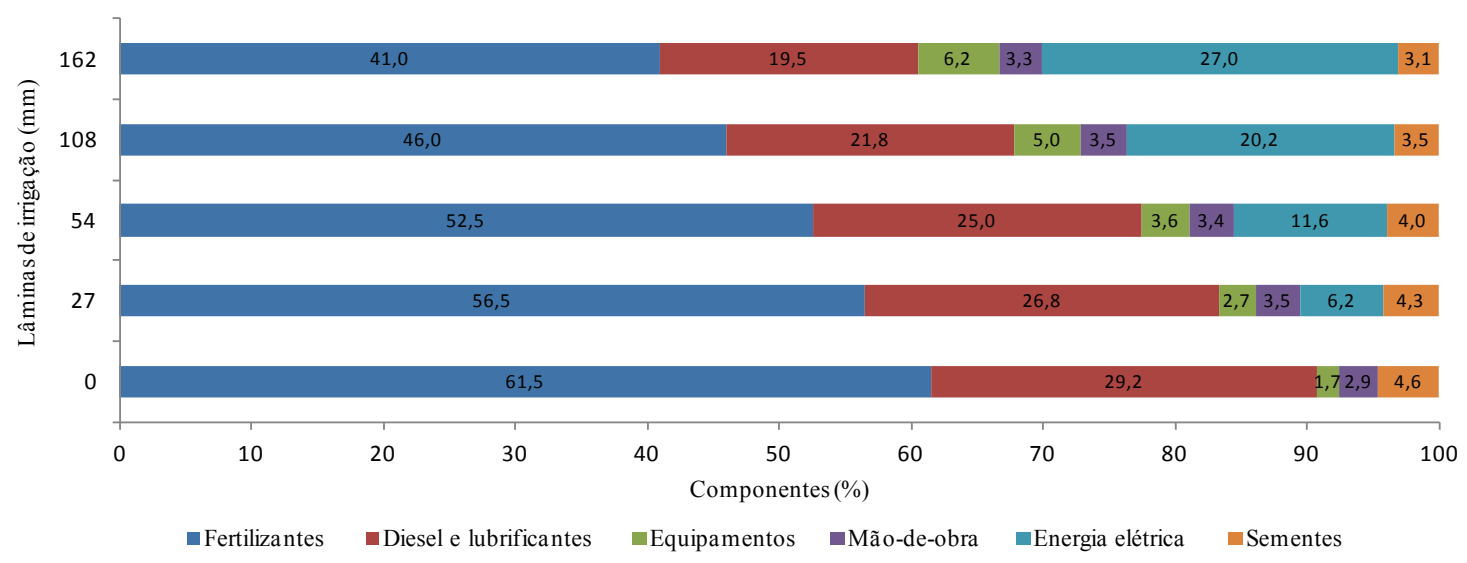

Figura 4. Representação das entradas de energia por insumo, para as duas cultivares de mamoneira, até 140 dias após a semadura, em função das lâminas de irrigação suplementar (Dourados, MS, 2010). 
extraída e a de energia empregada no cultivo, com o máximo de 108,0 mm, na lâmina de irrigação aplicada.

3. Nas entradas de energia, a energia fóssil presente nos fertilizantes, óleo diesel e lubrificantes foi a mais representativa, dentre todos os insumos utilizados na produção de mamona.

\section{REFERÊNCIAS}

ALBUQUERQUE, F. A. et al. Análise energética do consórcio mamona com amendoim. In: CONGRESSO BRASILEIRO DE MAMONA, 6., 2008, Salvador. Anais... Salvador: Seagri/Embrapa Algodão, 2008. 1 CD-ROM.

ASSENHEIMER, A.; CAMPOS, A. T.; GONÇALVES JÚNIOR, A. F. C. Análise energética de sistemas de produção de soja convencional e orgânica. Ambiência, Guarapuava, v. 5, n. 3, p. 443-455, 2009.

BERNARDO, S.; SOARES, A. A.; MANTOVANI, E. C. Manual de irrigação. 7. ed. Viçosa: Ed. da UFV, 2005.

CAMPOS, A. T. et al. Análise energética da produção de soja em sistema plantio direto. Global Science and Technology, Rio Verde, v. 2, n. 2, p. 38-44, 2009.

CAMPOS, A. T.; CAMPOS, A. T. Balanços energéticos agropecuários: uma importante ferramenta como indicativo de sustentabilidade de agrosistemas. Ciência Rural, Santa Maria, v. 34, n. 6, p. 1977-1985, 2004.

CARVALHO, S. et al. Energy performance of sprinkler irrigated maize, wheat and sunflower in Vigia Irrigation District. In: CONGRESSO BRASILEIRO DE ENGENHARIA AGRÍCOLA, 37., 2008, Foz do Iguaçu. Anais... Jaboticabal: SBEA, 2008. 1 CD-ROM.

CÉSAR, A. S.; BATALHA, M. O. Análise dos direcionadores de competitividade sobre a cadeia produtiva de biodiesel: o caso da mamona. Produção, São Paulo, v. 21, n. 3, p. 484-497, 2011.

CHECHETTO, R. G.; SIQUEIRA, R.; GAMERO, C. A. Balanço energético para a produção de biodiesel pela cultura da mamona (Ricinus communis L.). Revista Ciência Agronômica, Fortaleza, v. 41, n. 4, p. 546-553, 2010.

CORRÊA, M. L. P.; TÁVORA, F. J. A. F.; PITOMBEIRA, J. B. Comportamento de cultivares de mamona em sistemas de cultivo solados e consorciados com caupi e sorgo granífero. Revista Ciência Agronômica, Fortaleza, v. 37, n. 2, p. 200-207, 2006.

COSTA, F. X. et al. Disponibilidade de nutrientes no solo em função de doses de matéria orgânica no plantio da mamona. Revista Verde de Agroecologia e Desenvolvimento Sustentável, Limoeiro, v. 5, n. 3, p. 204-212, 2010.
COSTA, F. X. et al. Efeito do lixo orgânico e torta de mamona nas características de crescimento da mamoneira (Ricinus communis L.). Revista Engenharia Ambiental, Espírito Santo do Pinhal, v. 6, n. 1, p. 259-268, 2009.

CURI, S. Evapotranspiração e coeficientes de cultura da mamoneira (Ricinus communis L.) em Santo Antônio do Leverger - MT. In: CONGRESSO BRASILEIRO DE MAMONA, 1., 2004, Campina Grande. Anais... Campina Grande: UFP, 2004. 1 CD-ROM.

EICHOLZ, E. D.; SILVA, S. D. A. Qualidade de grãos de mamona em função da época de semeadura e ordem de racemo. Revista Brasileira de Sementes, Londrina, v. 33, n. 2, p. 261-271, 2011.

EMPRESA BRASILEIRA DE PESQUISA AGROPECUÁRIA (Embrapa). Centro Nacional de Pesquisa de Solos. Sistema brasileiro de classificação de solos. 2. ed. Rio de Janeiro: Embrapa, 2006.

EMPRESA DE PESQUISA ENERGÉTICA (EPE). Balanço energético nacional 2008, ano base 2007. Rio de Janeiro: EPE, 2008.

GAZZONI, D. L.; FELICI, P. H. N.; CORONATO, R. M. $\mathrm{S}$. Balanço energético das culturas de soja e girassol para produção de biodiesel. Revista Biodiesel, Monte Alto, v. 2, n. 16, p. 26-28, 2007.

HÜLSBERGEN, K. J. et al. A method of energy balancing in crop production and its application in a long-term fertilizer trial. Agriculture Ecosystems and Environment, Amsterdam, v. 86, n. 3, p. 303-321, 2001.

LÔBO, I. P.; FERREIRA, S. L. C.; CRUZ, R. S. Biodiesel: parâmetros de qualidade e métodos analíticos. Química Nova, São Paulo, v. 32, n. 6, p. 1596-1608, 2009.

MELO, D. et al. Energetic balance of soybean and corn production systems in a farm of the west of Paraná, Brazil. Acta Scientiarum Agronomy, Maringá, v. 29, n. 2, p. 173178, 2007.

PACHECO, E. P. Seleção e custo operacional de máquinas agrícolas. Rio Branco: Embrapa Acre, 2000. (Documentos, 58).

PAQUOT, C. Standard methods for the analysis of oils, fats and derivatives. 6. ed. Oxford: Pergamon Press, 1979.

SANTOS, R. F. et al. Análise econômica. In: AZEVEDO, D. M. P. de; LIMA, E. F. (Eds.). O agronegócio da mamona no Brasil. Brasília, DF: Embrapa Informação Tecnológica, 2001. p. 17-35.

SAVY FILHO, A. et al. IAC-2028: nova cultivar de mamona. Pesquisa Agropecuária Brasileira, Brasília, DF, v. 42, n. 3, p. 449-452, 2007. 
SAVY FILHO, A. et al. IAC-80 (Brasil integração): novo cultivar de mamoneira de porte alto. Campinas: Instituto Agronômico, 1984. (Boletim técnico, 85).

SEVERINO, L. S. et al. Avaliação da produtividade e teor de óleo de dez genótipos de mamoneira cultivados em altitude inferior a 300 metros. Revista Ciência Agronômica, Fortaleza, v. 37, n. 2, p. 188-194, 2006.

SILVA, S. M. S. e et al. Dotações hídricas em densidades de plantas na cultura da mamoneira cv. BRS Energia. Revista Brasileira de Ciências Agrárias, Recife, v. 4, n. 3, p. 338-348, 2009.
SILVA, A. N.; ROMANELLI, T. L.; REICHARDT, $\mathrm{K}$. Energy flow in castor bean (Ricinus communis L.) production systems. Scientia Agricola, Piracicaba, v. 67, n. 6, p. 737-742, 2010.

SOUZA, A. dos S. et al. Épocas de plantio e manejo da irrigação para a mamoneira: crescimento e produtividade. Revista Ciência Agronômica, Fortaleza, v. 38, n. 4, p. 422429, 2007.

WEISS, E. A. Oil seed crops. London: Longman, 1983. 